\title{
Conceptualizing Multilingualism in Medieval England, $c$. 800-c.1250, Edited by Elizabeth M. Tyler
}

G. Matteo Roccati

\section{CpenEdition}

\section{Journals}

Édition électronique

URL : http://journals.openedition.org/studifrancesi/1228

DOI : 10.4000/studifrancesi. 1228

ISSN : 2427-5856

Éditeur

Rosenberg \& Sellier

\section{Édition imprimée}

Date de publication : 1 décembre 2015

Pagination : 561

ISSN : 0039-2944

\section{Référence électronique}

G. Matteo Roccati, «Conceptualizing Multilingualism in Medieval England, c.800-c. 1250, Edited by Elizabeth M. Tyler », Studi Francesi [En ligne], 177 (LIX | III) | 2015, mis en ligne le 01 décembre 2015 consulté le 06 janvier 2021. URL : http://journals.openedition.org/studifrancesi/1228 ; DOI : https:// doi.org/10.4000/studifrancesi. 1228

Ce document a été généré automatiquement le 6 janvier 2021

\section{cc) (1) $\odot$}

Studi Francesi è distribuita con Licenza Creative Commons Attribuzione - Non commerciale - Non opere derivate 4.0 Internazionale. 
Conceptualizing Multilingualism in Medieval England, c.800-c.1250, Edited by Elizabeth M. Tyler

\author{
G. Matteo Roccati
}

\title{
RÉFÉRENCE
}

Conceptualizing Multilingualism in Medieval England, c.800-c.1250, Edited by Elizabeth M. TYLER, Turnhout, Brepols, 2011 («Studies in the Early Middle Ages», 27), pp. XII-368.

1 Le volume rassemble une quinzaine de contributions, les suivantes intéressent plus particulièrement la Rassegna. Bruce o'BRIEN, Translating Technical Terms in Law-Codes from Alfred to the Angevins, pp.57-76; Orietta DA ROLD and Mary SWAN, Linguistic Contiguities: English Manuscripts 1060-1220, pp. 255-270 (à propos d'un projet de catalogue électronique de manuscrits axé sur la langue utilisée); Andrew TAYLOR, Can an Englishman Read a "Chanson de Geste"?, pp.321-336 (sur la culture littéraire anglonormande); Thomas o'DONNELL, Anglo-Norman Multiculturalism and Continental Standards in Guernes de Pont-Sainte-Maxence's "Vie de Saint Thomas", pp. 337-356; David TROTTER, Intratextual Multilingualism and Social/Sociolinguistic Variation in Anglo-Norman, pp. 357-368. 